Kenneth Silver

Penultimate copy

\title{
Emergence within Social Systems
}

\begin{abstract}
:
Emergence is typically discussed in the context of mental properties or the properties of the natural sciences, and accounts of emergence within these contexts tend to look a certain way. The emergent property is taken to emerge instantaneously out of, or to be proximately caused by, complex interaction of colocated entities. Here, I focus on the properties instantiated by the elements of certain systems discussed in social ontology, such as being a five-dollar bill or a pawn-movement, and I suggest that these properties emerge in a distinctive way. They emerge in part because of a system that is far beyond and typically before the object that instantiates them. I characterize how emergence occurs in these cases, juxtaposing it with how emergence is typically discussed. I then consider whether their emergence is best framed as weak or strong as these notions are characterized in the literature, and I reveal what debates are central to answering this question. Though I will not resolve these debates, I do show a collection of views that would vindicate these properties as strongly emergent and downwardly causing.
\end{abstract}

\section{Introduction}

A five-dollar bill is a kind of thing of our creation, and as such metaphysicians discuss it and similar objects when they are talking about artifacts or social ontology more generally. In those discussions, we are typically considering how to think about the relation between the object qua five-dollars versus the object qua piece of paper-whether they are the same objects or distinct (e.g., Johnston 1992, Noonan 1993, Baker 2000), the process by which the piece of paper came to be a five-dollar bill (e.g., Searle 1995), or in virtue of what a five-dollar bill counts as money (e.g., Brynjarsdóttir 2018).

What is often left out of this discussion, however, is how we should think about the property of being a five-dollar bill. Whereas it may not be clear whether the object that has this property is identical with the colocated object that has the property of being a piece of paper, it can seem quite plausible to say that the property 'being a five-dollar bill' is not identical with the property 'being a piece of paper'. But if we want to say that 'being a five-dollar bill' is a property that physical objects can have, and that this property is not among but must in some way come from the fundamental physical properties, then it seems that the instantiation of the property of 'being a five-dollar bill' must in some sense be emergent.

In fact, we can be led to say the same thing about a great many properties of entities in our social world. Just as with the five-dollar bill, we can recognize how a piece of wood on a chess board has the property of 'being a pawn', and the event of moving it will have the property of 'being a pawn movement'. Or, we can see how someone's walking across the street without a crosswalk will have the property of 'being a jaywalking'. These are properties that we take to exist in some sense, and to have effects in the world. They also do not seem to be the properties of a fundamental physics, and yet we do not doubt that they are somehow related to such properties. So, it seems right to think that these properties too must be emergent. 
That it seems right to talk about emergence of these properties is a bit odd, though, as the topic of emergence is typically ${ }^{1}$ raised when discussing very different kinds of properties. Early discussions of property emergence involved considering properties of the special sciences, where these properties seem distinct from the properties of physics and yet clearly related. ${ }^{2}$ A more recent discussion has gone on in the philosophy of mind considering whether or not mental properties will reduce to or emerge from physical properties of the brain. But what is going on when we are talking about the emergence of these chemical or mental properties just seems wholly different from whatever is going on when we are talking about something's being a five-dollar bill. So, this paper will explore the apparent tension between the emergence of these properties and the ways in which emergence is typically understood.

Key will be the insight that these properties of the social world seem to emerge in the context of some broader system. Something can only be a five-dollar bill in the context of a certain monetary system. This system (whether we take it to involve other bills or our own expectations or intentions) involves many elements far apart from and before the existence of a particular five-dollar bill, and so the emergence of an instance of this property must be in some part grounded in the presence of this system. Much the same could be said for the property of 'being a pawn' or 'being a jaywalking' given the game of chess and our system of criminal law. These systems set the scene for the emergence of these properties, and it is the relation to them that sets apart the emergence in question as distinctive.

I begin in section (I) by specifying the question of emergence and orienting this discussion in relation to nearby issues in social ontology and philosophy of the social sciences. After this set-up, in section (II) I discuss more closely how to think about the existence of the properties in question and their relation to systems. In section (III), I show how their relation to these systems complicates their story of emergence, making it clear that their emergence is not capturable on extant models offered for chemical or mental properties. In section (IV), I delve somewhat deeper into different senses of emergence. I demonstrate how the sense in which these properties emerge likely depends on our background metaphysical views of the systems in question and on a number of other issues. Further, I show how a collection of views could be accepted to argue that these properties are strongly emergent. Section (V) concludes.

\section{Distinguishing the Issue at Hand}

First, it will be helpful to be clearer about what we are talking about when we talk about the emergence of some property. This is challenging insofar as the notion of emergence has been characterized in many different ways. On some ways of understanding emergence, it would seem to follow straightforwardly that the properties in question are emergent. For example, O'Connor and Wong say that "It is the thesis of emergentism that some basic properties are had by composite individuals" (2005: 664). The property of being a five-dollar bill certainly seems basic in some sense, and it can be instantiated by a piece of a paper as a composite object. If we were to take on this kind of view, we would need to consider more closely what it means for a property to be basic, but we would on strong footing to argue that the properties at issue are emergent.

\footnotetext{
${ }^{1}$ However, thinking of emergence is this context is not wholly without precedents. See Lawson (2013).

${ }^{2}$ See McLaughlin (1992) for a thorough historical overview of the different approaches taken on the emergence of the special sciences for by J.S. Mill, Samuel Alexander, and C.D. Broad among others.
} 
On the other hand, there are other common conceptions of emergence where it is less obvious that or how these properties are emergent. ${ }^{3}$ For example, Kim (1999) suggests that an emergent property is one that supervenes on some property or set of properties and yet will not reduce to those properties. Non-reducibility here is taken to mean that the instances of these properties are numerically distinct (non-identical). And the supervenience claim guarantees that the emergent property still depends upon or is fixed by some base of properties. So, for instance, one's being in pain supervenes on one's instantiating certain physical properties of the brain in that there is no difference in the pain property without a difference to the physical properties, and being in pain can be argued to be non-identical with those properties.

Framing emergence in this way, it is less clear exactly how to think about the emergence of properties like being a five-dollar bill, because we have to be thinking about what they are emergent in relation to. It is not too challenging (though it is not trivial) to argue that the instantiation of the property of 'being a five-dollar bill' is not identical with the

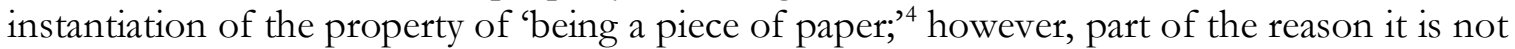
overly challenging is that that being a five-dollar bill does not even supervene on being a piece of paper. There can be changes to a five-dollar bill—what it signifies, that it even remains money-without changes to the piece of paper. We will discuss the appropriate supervenience base for this and our other properties below, but the point is that this is a conception of emergence that we have a harder time mapping our properties onto.

For the present, we will nevertheless take on board this conception of emergence involving supervenience and non-reducibility. This will make it much easier to position the emergence of our properties in relation to how emergence has been argued to proceed for other kinds of properties. However, I register some skepticism about understanding emergence in this way. ${ }^{5}$ We started by noticing that the property of being a five-dollar bill exists, by noting that it will not reduce to (cannot be identified with) any properties of fundamental physics, and yet noting that there is an expectation that there is surely some story to connect this property to the more fundamental ones. Short of accepting non-physical

\footnotetext{
3 There are other reasons for looking for a different view of emergence besides. I mention O'Connor and Wong's account because it seems so apparent that our properties will be classified as emergent on it, and part of our aim here is to provide more reasons for thinking that these properties are emergent. That said, I do think that their account is neither necessary nor sufficient: If macroscopic extended simples are possible, perhaps such emergent properties could be instantiated by them. And we may think that composite objects can themselves instantiate fundamental physical properties (e.g., charge or spin). So, I do not think their gloss really captures what is essential to emergence.

${ }^{4}$ For this, we could borrow from the barrage of arguments that have been marshalled to argue for non-identity in the context of material objects or mental properties. For example, we could argue on the basis of causal differences: a five-dollar bill could be argued to have a different causal profile than that of being a piece of paper. (See, inter alia, Heil \& Mele [1993], Robb \& Heil [2019], and the many works cited within these for arguments of this kind in the context of philosophy of mind.) We could argue on the basis of multiple realizability: a five-dollar bill could have been instantiated by something other than a piece of paper if we had different conventions. (See, inter alia, Polger \& Shapiro [2016] and Bickle [2019] for systematic discussions purely on this topic, and see Putnam [1967, 1973], Fodor [1974], and Lewis [1972] for the relevant history of arguments of this kind.) And there are more arguments besides. I only gesture towards how we could argue, however, because it is sufficient to see how the very resources appealed to by emergentists in the philosophy of mind, say, could be just as helpful for our purposes. Some will object to the deployment of some of these arguments, but those writing about the emergence of mental properties will not be a better position to defend themselves.

${ }^{5}$ I suspect that we often understand it this way because it raises a puzzle worth addressing about how it is possible for entities to be non-identical and stand in a relation of supervenience. But this itself does not seem to be the core of the concept of property emergence.
} 
properties as existing in a Leibnizian pre-established harmony, there will always need to be a story for where non-fundamental properties come from, or how they are grounded in the physical. So, I think the presumption should be that these properties emerge, and exploring their supervenience base and that to which they will not reduce is a good way to determine the source of their emergence. ${ }^{6}$

With this conception of emergence picked out, we are set to look more closely at our properties to think about how they relate to systems and how this is relevant to their emergence. Before we do this, however, I want to briefly juxtapose this debate over the emergence of properties in social systems with two close-by debates often discussed by those working in social ontology of philosophy of the social sciences. This will hopefully clarify the ways in which the debate at hand is to be distinguished from these other discussions.

First, a familiar debate surrounding items of the social world involves the debate between so-called methodological individualism and holism. Holists argue that we need at least some social concepts (such as the concept of a workers' union, or unemployment, the crime rate, etc.) to provide adequate explanations of phenomena studied in the social sciences (e.g., Kincaid 1986; Sawyer 2002; Zahle 2014a; Zahle \& Kincaid 2019). Methodological individualists, on the other hand, argue that adequate (even superior) explanations can be given entirely in terms of our understanding of individuals and perhaps their relations to one another (e.g., Popper 1945; Watkins 1957; Brennan \& Tullock 1982; Elster 1983; Demeulenaere 2011; List \& Spiekermann 2013; Rapport 2017; Mitrović 2017).

This is an interesting and live debate, where I take it that individualism indeed might be right when it comes to certain concepts discussed in the social sciences, though perhaps not for others. I am generally sympathetic to holism, but how these debates are resolved is orthogonal to our question here. We are concerned directly with the nature of properties of particular objects or events, not with the explanatory relevance of social science concepts. That debate concerns explanation, not existence, and it is the existence of these properties that concerns us. ${ }^{7}$

A second way that properties of the social world are often discussed involves how various social features relate directly to the mental states of individuals. So, for example, joint or group agency may be taken to involve the coordination of individual intentions, and we can recognize that there is a debate concerning whether the intentions of individuals is sufficient, or whether those intentions requires content involving plural agents, whether these intentions must be shared, or whether groups themselves must have sui generis intentions. Similar conversations concern how to think about group belief or group understanding, for instance, and these and other conversations are generally carried out under the heading of issues in collective intentionality. ${ }^{8}$ What tends to be at issue is whether some social phenomenon can be reduced to what goes on in individuals, but it is a conversation about existence, rather than

\footnotetext{
${ }^{6}$ To be fair, Kim himself thought that supervenience and non-reducibility alone were poorly suited to sufficiently characterize emergence. He wrote,

What we have in supervenience and irreducibility, therefore, are two essentially negative conditions, and they do not amount to a positive account of what emergence really is...I believe that one pressing item on the emergentist agenda is to provide an illuminating positive characterization of emergence. ([emphasis in original], 2006:557)

7 That said, there are ontological questions and debates close by. We may wonder whether we should accept the existence of groups or organizations, for instance. Or we might consider whether accepting non-reducible social science concepts entails certain ontological commitments to serve as the truthmakers of claims involving those concepts.

${ }^{8}$ See Schweikard \& Schmid (2013) for a thorough introduction to these topics.
} 
explanation. It is also a question of whether the phenomenon reduces to the mental states of individuals.

It is not entirely clear how the question of the properties that are our focus intersects with this literature on collective intentionality. The debate over the reduction of these properties is not likely to be a debate about whether they reduce entirely to other mental properties. (And, even if so, it may just as well be a matter of collective as well as individual mental properties.) I will save this question of the relation between the systems at issue and properties of our minds for below; however, we may worry that in even admitting this much we are inviting a challenge to the interestingness of the emergence at issue.

There is already plenty of work on how to think about the emergence of mental properties. So, there is a temptation to say that our properties emerge in a similar fashion or as a species of mental property emergence. ${ }^{9}$ For now, I merely want to flag this issue and to say that how these properties are instantiated will prove interesting enough in its own right. Given that, let's move on to consider how we should think about the properties in question.

\section{The Properties of Elements of Social Systems}

The common thread in the examples that concern us here is that these are properties that stand in some relation to socially constructed systems (e.g., our economy, our system of laws, the game of chess). It can be hard to see exactly what this relation amounts to-whether these properties are parts of those systems, or instantiate them, or exist in the context of them-but we can start merely by recognizing that some properties are related to systems in some way. At the very least, we can appreciate that these are properties of elements of these systems, as opposed to properties of those systems themselves. Call the social properties had by elements of these systems system-based social properties. ${ }^{10}$ Though it is not immediately clear what it is to be a social system property, we certainly know one when we see it. We engage with these social systems on an everyday basis and are constantly acting within them. These are features of our social world that we create and collectively accept, the objects of which are the subject of social ontology.

\footnotetext{
${ }_{9}$ Alternatively, we may think that these properties emerge from mental properties - that mental properties are that base on which these properties supervene and will not reduce. I will leave this issue largely unconsidered. This turns on the nature of the systems under discussion, and we will briefly take up this issue below (in section IV) as indicated. I leave it to the side, however, because it shouldn't make a difference as long as we assume that mental properties themselves at least supervene on physical properties (as emergentists about these properties would maintain). Given the transitivity of supervenience, then our properties will still supervene and not reduce to physical properties, and so could be understood as emergent relative to them on the characterization above. The emergence of these properties is characterized in section (III) relative to this physical base, but it is worth noting that even if we were to only talk in terms of these properties as emerging from mental properties, the distinctive elements brought out in that section would still be present.

10 This label allows for an easy contrast with mental and physical properties, though it does perhaps invite some ambiguity. To be clear, again, our concern is for those properties of elements of social systems, not properties of the social systems themselves (as wholes). The former are properties like 'being a five-dollar bill' or 'being a pawn,' whereas the latter are properties such as money's property of 'being a medium of exchange' or chess's property of 'being an intellectual game.' Though the ambiguity is unfortunate, notice that the ambiguity here is not unique, as a similar ambiguity is possible when thinking about mental properties. We may be used to thinking of mental properties as properties of elements of the mind, but 'mental properties' could also be misread as being properties of the mind itself, such as 'being clever' or 'being of sound memory.' There is, however, a separate and interesting debate concerning the causal efficacy of social structures themselves. See Elder-Vass (2010, 2014a, 2014b) and Wahlberg (2014a, 2014b), Zahle (2014b).
} 
I want to be clear to say that our concern here is merely with these properties of these objects of social ontology. We really do take there to be pawns and pawn-movements and five-dollar bills, and we take them to be a part of the physical world. ${ }^{11}$ Insofar as we do, there must be a story for how the properties of these objects square or relate to other kinds of properties in the physical world. That they do so relate via emergence is the claim of this paper, but it must be acknowledged that it is just a claim about these particular kinds of properties, as opposed to other interesting properties of our social world (e.g., the other kinds of properties discussed in fn.10).

It's also not immediately clear what it takes to be among the social systems in question. ${ }^{12}$ We should acknowledge that there are deep metaphysical issues surrounding systems even if we have one in mind that we have a fairly good grip of. For example, certain objects will have the property of being a pawn when they are part of a game of chess, and so properties involved with an unfolding chess game will depend to some extent on how exactly we understand chess metaphysically. Many will deny flat-out that the game of chess exists or can in any sense be a part of the furniture of the world, but proponents within social ontology will be amenable to talking about the existence of chess and chess-related properties.

Clearly, chess as a game involves a system of rules, many of which we may take to be constitutive of the game itself (Lewis 1979). These rules established what kind of items are in chess and what kinds of things can happen in a chess game. So, for instance, they tell us what counts as a bishop, a pawn-movement, checkmate, and so on. We can think of this as a list of chess types, such that a particular game of chess involves various tokens of these preestablished types. For example, the rules of the game delineate what it is to be a pawnmovement (what kind of movement in the game is of the type 'pawn-movement'), and then in playing the game we can instantiate a token of that type by moving a pawn in accordance with the rules. It is the instantiation of these tokens of previously established types-of systems that are already established - that is the critical element to the distinctive nature of the emergence of these properties, as discussed below.

Though with chess we are dealing explicitly with rules, we are largely dealing with the same issues when we expand to think about the other mentioned social systems involving our system of currency/banking or our system of laws. ${ }^{13}$ There may not always be a rulebook ready to hand for these other systems, but there are the same concerns having to do with what events constitute the establishment of various elements of the system, whether it is explicit acts of rule-setting or changes in behavioral dispositions, etc. In each case, it seems that we create social systems by creating a set of related types. And a property of an element of a social system as I have been discussing them will be a token of one of the pre-established types.

Indeed, I take this to extend beyond the explicit, consciously created systems on which we are focused. There may be many systems that we create, though not consciously. And

\footnotetext{
${ }^{11}$ It may be controversial exactly how to think about the existence of these objects, whether they are genuine material objects or else that they are abstract but somehow embodied. (Korman [2020] has recently argued for this kind of existence for establishment like restaurants.) It is interesting that while pawns and bills can have mass and location, money can exist purely digitally, or that we can play chess without pieces just by calling out our moves to one another. However, we do not need to settle this question here. Even if pawns were abstract objects, in our cases the pawn is embodied such that there is still a physical object that has the property of being a pawn, and this property must be reconciled with the broader array of physical properties for physicalism to be true.

12 It may even be that there are properties instantiated in the social world that are not a part of social systems (and so that will not emerge this way). These would be social properties that are not system-based. Though no example comes to mind, what follows is not meant to fully capture the emergence of every kind of social entity. ${ }^{13}$ Closely related to all of this is how we should think about the existence of social institutions more generally and institutional facts (facts involving elements of those institutions).
} 
though social systems can emerge all at once in a baptismal fashion, we may also think it's possible for a system to gradually emerge. For example, linguistic items have semantic properties, and we may think that they are also emergent as system properties. Language is surely best conceived of as a system, ${ }^{14}$ though the system of language may emerge slowly and unconsciously as a matter of tacit conventions. ${ }^{15}$ It may be a mistake to think of semantic properties in this way, but the point is that expanding our conception of systems allows us to re-examine familiar properties (hopefully in a way that it is not merely putting old wine in new bottles).

How we understand rules and systems is important, and below I will suggest that exactly how we think about the metaphysics of rules in particular influences how we evaluate the emergence of properties within these systems. For now, though, what matters is that there are different ways of conceiving of these systems while agreeing that they exist and can have elements that instantiate them. The question becomes, then, how should we think about the emergence of the token property instances of the elements within these systems?

\section{The Emergence of Properties in Social Systems}

If system-based social properties are indeed emergent, the way in which these properties emerge would have to be quite distinctive from how emergence is typically characterized as proceeding. Though several different models of emergence have been offered, none of them capture how emergence could work in the context of a system.

As we saw, emergence is often understood in terms of supervenience and nonreducibility. Given this, we can first notice that in the typical discussion of emergence in the context of philosophy of science or mind, we are almost always talking about cases where the emergent seems to happen at one place and time. The emergent property is either instantiated by the very same object that instantiates those properties on which it supervenes yet will not reduce, or else the object(s) instantiating those properties are colocated with it.

The emergentist about mental properties, for example, will usually claim that mental properties are different in kind and irreducible to any candidate physical properties, meaning mental properties cannot be understood in terms of or thought to consist in physical properties of the brain. ${ }^{16}$ However, this emergentist will say that those mental properties nevertheless supervene on certain physical properties of the brain. Given supervenience and the presumed colocation of the instances of these properties, the typical metaphorical understanding of emergence seems to be that mental properties emerge upwards from the physical properties of the brain. That is, the mental properties seem to emerge directly out of physical properties.

Thus, emergence is traditionally conceived of as a synchronic relation between the emergent properties and the physical properties on which they supervene, where the properties in question appear to emerge upwards from the properties of their supervenience

\footnotetext{
${ }^{14} \mathrm{It}$ is much too quick to simply say that language is a system, so the property of something's having a certain linguistic meaning can emerge as a system property. The metaphysics of language is instead a possible application of the idea of system emergence that I merely mean to gesture towards. See Bickhard (2008) for a connection between language and social ontology in the importance of convention.

${ }^{15}$ We may say something similar for much of the law. While we do write down and enforce many laws, much of the law forms as a matter of patterns of judicial decisions rather than as a matter of explicit law-making.

${ }_{16}$ Though non-reductive physicalists about the mind will maintain that mental properties count as physical as well in some sense, or are derivatively physical (Bennett 2008).
} 
base somehow in virtue of the relation of the elements in that base. We could say that the instantiation of these emergent properties is metaphysically explained by the instantiation of the properties of the supervenience base. This is how the properties of the special sciences were originally thought to emerge by the early British Emergentists (McLaughlin op. cit.). The idea was that the organization and structure of the elements of the base led to the emergence of further properties. It was the structure of elements, not merely the base elements on their own, that would yield emergent properties.

More recent philosophers thinking about emergentism have considered other ways to conceive of emergence that are not simply a matter of the structure of the elements in the supervenience base. O'Connor and Wong (op. cit.), for example, gives a picture on which properties emerge as a matter of the complex interactions of the elements which cause the emergent properties to emerge. That is, the instantiation of emergent properties is caused by the instantiation of non-emergent (or at least more fundamental) properties, and that these new properties are emergent (the fact of their emergence) is metaphysically explained by facts concerning the complex interaction that preceded it. So, on their picture emergence is diachronic and causal instead of synchronic, though the emergence is proximately caused by the organized complexity of the elements in the purported base.

Similarly, Kirchhoff (2014) delivers a model of diachronic emergence within dynamic systems, in this case where complex interactions cause an emergent process to unfold. Even more radical views of emergence can be found in Humphreys (1996, 1997), which claim that emergence is a matter of the fusion of the base elements (such that those base elements no longer exist on their own to offer worrying causal competition with the fused product), and in Ganeri (2011), which offers the view (in part on the behalf of ancient Indian philosophers) that the elements of the base transform into the new emergent substance.

Though emergence is depicted on these views as being diachronic and causal, what's crucial to notice is that they still all involve proximal causation. That is, that which emerges does so immediately as the product of either the interaction of the same base elements (that all remain present as the property emerges), or else the fusion of these elements or their transformation. While these may provide fruitful models for the emergence of certain properties within the social sciences, or even for mental properties, it seems immediately clear that system-based social properties discussing do not emerge in these ways.

The property of something's being a pawn surely does not emerge as a matter of the interaction of any of the physical properties of the piece of wood that constitutes its physical base. The wood may have the structure of a pawn, but pawn-ness does not emerge locally as a property merely because it has that structure. (A chipped off piece of wood from a tree that happened to have the same shape would not be a pawn.) Neither is it a pawn because of some degree of organized complexity in the elements of the object that instantiates it. The molecules in the wood are not so complex that they somehow cause the instantiation of the property of being a pawn or of a pawn movement, nor do they seem to fuse or transform into a pawn. And what we have said about the pawn seems equally true for the property of being a fivedollar bill or being a jaywalking.

The emergence of properties of elements within social systems more generally cannot easily be construed as occurring as a matter of the interaction of the properties of actual objects that instantiate them (or the properties of colocated objects). This is because the emergence of system-based social properties at least partially depends on the system of which it is a part. It's not that the physical properties at hand somehow bubble-up and miraculously birth new irreducible properties; instead, system-based social properties are a matter of physical 
properties fulfilling the criteria for the presence of extra properties, the blueprint for which were created at an earlier time as part of separately creating the system.

Now, there is a sense in which it may still seem appropriate to think of system-based social properties as synchronically emerging. After all, the object instantiating the property of being a pawn is at least colocated (if not identical) with the object instantiating the property of being a piece of wood. And though the property of being a pawn does not supervene solely on the property of being a piece of wood, that property is a part of its supervenience base. There will be no difference to the pawn (concerning its movement, say) without some difference in the wood.

That said, it seems on balance inappropriate to think of the emergence at hand as synchronic. There is simply a lot going on in these cases beyond when and where these properties emerge, as they emerge within the context of a larger social system that proceeded them and of which they are a part. ${ }^{17}$ These properties would not exist without the system in question, and differences in the system and its causal history can make for differences in the emerging property. Further, there will be no differences to these properties without some difference to this broader base of properties. As such, we should say that the supervenience base for the property of being a pawn movement and so on extends far beyond and before the existence of other physical properties of the object instantiating the social system property (or the physical properties of other colocated objects). That is to say, the supervenience base of properties that fix our system-based social properties will be at least partially non-local.

The non-locality of the supervenience base is meant to mark the emergence at issue as distinctive from how it is typically discussed, but this is not to say that maintaining this nonlocality is novel in the literature. ${ }^{18}$ Authors such as Brian Epstein (2015) have argued that many items of the social world do not supervene on whatever objects locally constitute them. For example, although the Supreme Court may be constituted by the current members, facts about the Supreme Court do not supervene purely on the facts about those individual members (ch.11). Instead, the supervenience base will be much larger to include the origins of the legal institution itself. Although we are talking about properties, not objects like groups, the same points apply. ${ }^{19}$

Indeed, even though we are contrasting the way system-based social properties emerge from the models of emergence for mental properties, for instance, this question of the nonlocality of the supervenience base may reasonably extend beyond the social. Those willing to entertain externalism about mental content, for example, will accept that part of the individuation conditions for a certain mental state or content of such a state may depend on circumstances outside of the mind (Lau \& Deutsch 2019). Whether my memory is of water

\footnotetext{
${ }^{17}$ It is worth noticing that Silberstein (2017) has recently discussed a kind of emergence dubbed 'contextual emergence.' Though I suspect there is some connection between his notion of contextual emergence and how I portray these properties as emerging in the context of a system, it is not entirely clear how to characterize this connection precisely. Insofar as he takes contextual emergence to be the norm amongst properties that actually should be thought of as emergent in the sciences, our views come apart. Further, I have more to say about the nature of social systems in particular and how they suggest diachronic emergence.

18 I thank a reviewer for drawing me to discuss the clear precedents here.

${ }^{19}$ Interestingly, however, Epstein denies that he is talking about emergence in his depicting groups as failing to supervene on their members. He says, "Emergence is compatible with supervenience. The point we have just discussed, on the other hand, is the failure of supervenience ([italics in original], op. cit., 167). I agree that demonstrating a failure of supervenience is insufficient to establish emergence. However, we are talking about properties that will not reduce to their supervenience base, and that are causally efficacious in their own right (as we will see below). So, they do seem to fit onto our conception of emergence. To be fair, Epstein is talking about objects such as groups, and is less focused on how to think about the properties those groups instantiate.
} 
instead of twater, for instance, may depend on the causal history of how I came to acquire the concept. So, authors far beyond social philosophy have been willing to entertain supervenience bases including distant items. ${ }^{20,21}$

What is more distinctive of the approach here is our attempt to reconcile the claim that these properties have non-local supervenience bases with the claim that they are emergent. Let's grant for the moment that they are emergent; after all, they do seem to supervene on some base and be non-identical with it. Given that the base is primarily non-local, however, it is less clear how to frame this emergence. I have suggested that the supervenience base for these properties makes it inappropriate to think of them as emerging synchronically. If it is not quite right to think of their emergence as synchronic, does that mean that it is better thought of as diachronic (or perhaps as a kind of mixed synchronic/diachronic case, as Sartenaer [2015] considers)?

Well, it is true that the supervenience base for these properties includes historical features of these systems, and these properties will counterfactually depend on the past establishment of these systems. And it is also true that the property instances in question, as events, have causes. However, it does not seem that the systems themselves, or even the events of their establishment, are productive or direct causes of the instantiation of system-based social properties. Chess as a game may need to exist for me to move my pawn - its existence may be a necessary background condition - but the primary causes of my pawn movement are my mental states about what move is best. Even our playing to begin with will be caused by our remembering that there is this game and feeling like playing, not by the creation of the game itself. This makes it sound like system-based social properties do not emerge diachronically as a product of the system.

That said, even if the system itself is only a background condition for the causation of emergent system-based social properties, the primary causes of these properties should also be within the supervenience base for these properties. And this is true even if they are not a part of the system. ${ }^{22}$ For example, I can be caused to walk across the street by a belief/desire about something on the other side, and I may have no awareness of the traffic laws that

\footnotetext{
${ }^{20}$ Raising this point about external mental content may make us wonder whether and how this complicates the more standardized story for the emergence of mental properties. Should we say that many mental properties (insofar as they have content in part set externally) should also not be modeled as emerging synchronically? This is not the place to explore this question, but I will say that I am disposed to think that the externality of mental content should influence the story of the emergence of mental properties in some way. Where this issue has tangentially been relevant concerns the question of whether mental states with wide content can still be causally efficacious. See Williamson (1998), Gibbons (2001), and Yablo (2003) for arguments in the affirmative. If successful, and if these mental properties are emergent, then this would suggest that the properties are strongly emergent (as discussed below) however they emerge.

${ }^{21} \mathrm{I}$ also do not mean to suggest that the matter of the possibility of such supervenience bases is settled. Though I think considerations speak highly in favor of granting that items can supervene on other items not proximal to them, there will of course be a story to tell should we want to bite the bullet. We could argue when considering the property of being a pawn, for instance, that the properties of the piece of wood are sufficient to constitute the supervenience base in question if we allow relational features of the wood to its social environment to count amount those physical properties in the base. This would be even more plausible if we independently thought that multi-place, relational properties reduce to one-place properties. Even if we are able to twist ourselves into a view on which the emergence here technically involves only the synchronic interaction of properties, however, the emergence at hand would still be a matter of some item's relations to the system in question, which is a dramatic departure from other models of emergence.

22 This is insufficiently careful if we take supervenience and causation to be relations with different relata. However, depending on the relata we choose, there should be a way to translate the relevant talk here to make roughly the same point: that the emergence is indeed causal.
} 
constitute jaywalking. In this case, I think we should say that my belief/desire not only caused the event of my walking but also caused the event of my jaywalking (as an unintentional action), even though this cause is not a part of the relevant social system. The property of being a jaywalking that the event instantiates supervenes in part on the properties of my having a belief/desire in this case.

On this way of understanding things, the emergent property is caused by elements in its supervenience base, and so the emergence does seem to be diachronic. How this causation works, though, still seems quite different from how diachronic emergence works on the picture provided by O'Connor and Wong (op. cit.). The causation in question is closer to striking a match in a room full of oxygen than it is a matter of the complex interaction of elements. ${ }^{23}$ Systems establish the conditions whereby events instantiating them are caused. So, the relational properties had by items like my pawn-movement or my jaywalking play a much more significant role in emergence insofar as they involve the relations to those systems.

What's historically interesting about conceiving of the emergence of system-based social properties as proceeding in this way is that several philosophers writing about emergence have at times expressly written-off the possible importance of relational properties. Tim Crane notes that it would be "somewhat perverse to describe [relational properties] as "emergent" (2001:213), though he doesn't consider that other properties could be emergent in virtue of relational properties. Pereboom (2002:508) makes nearly the same point ${ }^{24}$ and I think the same mistake. While it would surely be odd to think of bare relational properties as emergent, we can see that an item's relation to a system can be such that a new property does emerge: a property of the item relative to the social system of which it is a part.

What's more, I am not alone in maintaining that relational properties might play an important role in emergence. Though the emergence of system-based social properties is quite different from how discussions of emergence typically proceed, their emergence is quite similar to one instance of emergence discussed in the literature: the emergence of instances of patterns discussed in Humphreys (2008). There, Humphreys suggests that when patterns emerge from random phenomena, that emergence "...is an essentially historical phenomenon - whether an instance of a pattern is emergent or not depends essentially upon the process that generated it" (434). He goes on to say, "It is therefore impossible to determine whether a pattern is emergent by looking only at synchronic relations between the pattern and the spatial array of elements that comprise the pattern" (ibid.). So, for Humphreys pattern emergence also depends on the relation to extrinsic features (in his case, facts about the past).

\section{But What Kind of Emergence is It?}

Assuming only what we have about emergence has been helpful for framing the distinctiveness of our properties. However, given the sparseness of this characterization, there are still different ways we might think about emergent properties - some weaker, some stronger. And much of the debate about emergent properties concerns clarifying and arguing between these

${ }^{23}$ Though precisely how to distinguish these models of causation is a challenging topic within the philosophy of causation itself. We regularly do distinguish between primary causes and background conditions in natural language, and so a view of caution that cannot do justice to or invalidates this distinction may not have the resources to distinguish my view of emergence from O'Connor and Wong's.

${ }^{24}$ Specifically, he claims that something's not being predicable from basal conditions, such as relational properties, is insufficient to guarantee that those properties are emergent (ibid., fn.16). This does seem right, but it does not show that relational properties cannot be crucial to the emergence of certain properties. 
different senses of emergence. In this section, I want to draw out a few of these senses and show what they suggest about social system property emergence.

If we accept that the instances of system-based social properties are not to be identified with any of the properties in their supervenience base, then the emergence at hand will at least transcend a kind of emergence-lite often gestured towards. For Silberstein \& McGeever, for instance,

A property of an object or system is epistemologically emergent if the property is reducible to or determined by ${ }^{25}$ the intrinsic properties of the ultimate constituents of the object or system, while at the same time it is very difficult for us to explain, predict or derive the property on the basis of the ultimate constituents. Epistemologically emergent properties are novel only at a level of description. (1999:186)

Epistemological emergence, then, is a matter of what is novel to us perhaps, but is not something that is a novel feature of the world. Our properties at least seem more robustly emergent than in this sense, then, as they are novel and non-reducible.

A slightly more robust conception of emergence from the literature is the notion of weak emergence. Properties that are weakly emergent may not reduce to lower-level properties of their supervenience base, but there is some important sense in which they are deducible from or are generated by elements at a lower, more fundamental level. Different authors have specified this in different ways. Chalmers (2006), for instance, suggests that weakly emergent properties are deducible given the laws and the initial conditions of the fundamental physical domain, and he retains the epistemic or subjective element of something's weakly emerging when it is unexpected to us given those laws. In contrast, Bedau (1997) captures this element of surprise by understanding weak emergence in terms of items that are deducible in principle from the dynamic laws of a system and the initial conditions, but where these properties will not be recognized without actually simulating the system (seeing it played out).

Are system-based social properties, as we have come to understand them, weakly emergent then? Though novel, there is a clear sense in which these properties are not surprising or unpredictable in the least. We invent them, after all, we do not happen upon them as unexpected phenomena in the world. From the perspective of fundamental physics, however, they are unexpected. The laws of the United States are not derivable from the laws of physics. Given just those laws and the initial conditions, we would not predict jaywalking and the like.

There is this question, though, of whether system-based social properties are still deducible in principle from the fundamental laws and the initial conditions. How we answer this question, however, turns on how we feel about a number of interesting debates. Insofar as these properties are inventions of our agency, for instance, whether or not we think their emergence is deducible from the fundamental laws and the initial conditions depends on whether or not we accept determinism, or rather whether we accept that the truth of determinism undermines our having genuine alternatives in action. Christian List (2019:ch.4), for example, has recently argued that determinism at the level of fundamental physics is compatible with indeterminism at the psychological level of nature at which we make decisions and act. So, an instance of my moving my pawn would not be deducible even in principle from

25 This disjunction complicates matters somewhat in terms of precisely which properties will qualify as epistemologically emergent. To distinguish their notion from other specifications of weak emergence, I am just treating their cases as those where what really emerges is a novel description or simple explanation for phenomena, where there are no new properties. 
the laws of physics and initial conditions. ${ }^{26}$ On the other hand, if we accept that determinism at the level of physics applies to actions, this suggests that the emergence of our properties is deducible and so weak.

Whether or not the properties are ultimately deducible also depends on how we understand the metaphysics of social systems themselves. In particular, it will likely turn on how we are thinking about the rules constitutive of those systems. We can recognize that there may be broad disagreement over the nature of those rules, the types that they set out, or how they are established. This will lead us to disagree about the type of emergence at issue.

For example, we may follow Searle (op. cit.) in maintaining that what is involved in the creation of these systems is the establishment of a set of status functions, using the 'X counts as $\mathrm{Y}$ in context $\mathrm{C}^{\prime}$ schema, to denote which items will count as what and in what conditions. So, we may take the rules to be pegged to particular historical speech utterances. If we had this kind of view, then the establishment of the system itself will be deducible from the more fundamental level (assuming determinism). Further, given these past events and the determined actions of agents, we will further be able to deduce the occurrence of acting within that system, such as pawn-movements and the like. ${ }^{27}$

On the other extreme, we may be Platonists and take the rules at issue to be abstract existing entities, and to involve the creation of abstract universals to be instantiated by the instances of the system. If we had this kind of view, which is not an odd view to have about the metaphysics of rules ${ }^{28}$ then we would not say that the establishment of the rules and system are deducible from physics. We can make all of the utterances that we want, but it will be a hard question as to when these utterances suffice to generate new abstract objects constitutive of a system. In this case, we could not deduce from the physics when a new system is created, nor could we deduce when that system is instantiated.

We will not settle here how to think about the rules constitutive of these systems or whether they might in the end be deducible from the physics. ${ }^{29}$ But this hopefully shows how the contours of such a debate will be relevant to whether we conceive of the emergence of system-based social properties as weak in this sense. If these properties cannot be deduced from the physics, then we may take them to be 'strongly emergent' by contrast. However, strong emergence is often conceived not in terms of non-deducibility, but instead in terms of

26 Though the systems in question will be a product of our consciousness and agency, we can see how this does not mean that their emergence is necessarily derivative of the emergence of consciousness. Even if there are new fundamental laws that must be added to capture consciousness, adding them is still insufficient to deduce the emergence of our social systems if these laws are indeterministic, as these systems are a product of our free choices. We cannot deduce, for instance, that we will make the rules of chess exactly as we do. Once those rules are made, however, they can be added to the catalogue of laws to predict our future behavior. That said, if our actions are free in this sense, then even a regular instance of my moving my pawn will not be deducible even given the laws of physics, psychology, and the rules of chess; as I might choose otherwise.

27 The same would be true I think if we took the rules of a social system to be understood entirely in terms of the mental states of individuals charged with governing or acting within that system.

${ }^{28}$ For instance, Hédoin (2015) argues that constitutive rules cannot be fully accounted for by reductionistic views that understand them only in terms of historical behavioral trends.

${ }^{29}$ To not undersell the significance of this question about how to ground these rules, however, we should recognize just how close we are in this discussion to the vast literature on the nature of normativity. We are not only wondering what makes something a pawn-movement, but what makes that pawn-movement appropriate or correct. And we may well think that historical facts there are about past utterances are insufficient to ground facts normative features like correctness. Relatedly, we can notice that it is not simply a matter of someone or other's making certain utterances that is important for the creation of systems like chess. Also critical is that the utterers have the right kind of authority such that it's their utterances that matter for setting the rules of chess. 
causal impact. ${ }^{30}$ The more widely discussed feature of strongly emergent properties is their efficacy. If a property is truly an emergent, 'new' property, then it should be able to do new things. ${ }^{31}$ It should have some effect in the world that cannot be causally explained by the lowerlevel physical properties to which the emergent property supposedly will not reduce.

Given this characterization, should we think that system-based social properties are emergent in this sense? Well, as we saw, the emergence of our properties involves objects that stand in certain relational features to the background systems. As such, our acceptance of possible efficacy of these properties depends on how we feel about the possibility of wide causation, or causation by thing in part in virtue of its relations to non-local phenomena. Footnote 20 catalogues proponents of wide causation in the case of mental content in particular, and see de Muijnck (2002) for a more general defense of the efficacy of relational properties. However, this issue is far from settled, and see Wahlberg (2020) for the opposing view that such properties cannot properly manifest causal powers. ${ }^{32}$

The strong emergence of our properties in part turns on the outcome of this debate about wide causation. Putting this debate to the side, however, I think it is interesting to see how there is quite a strong prima facie case for the efficacy of system-based social properties. Your pawn-movement may cause my rook-movement; an instance of jaywalking may cause the giving of a citation; an objection in a court of law may cause a judgment of 'sustained'. The systems involved not only include many elements, but they also involve rules (even sometimes genuine causal rules) for how those elements interact across time. So, system-based social properties can at least cause the instantiation of further properties in that system. ${ }^{33}$

It may even be that the instantiation of certain properties can only be caused by previous property instantiations of the same system. Someone cannot be checkmated unless they find themselves in a particular chess situation having followed the rules of chess the entire game. By the same token, a document can only have the property of being notarized if it is caused to have a signature on it by someone previously certified as a notary. These are events that lower-level, physical properties cannot cause.

We might be tempted to think that a social system property's only causal contribution is at the level of sociality, and to say that this is sufficient for strong emergence. ${ }^{34}$ But some

\footnotetext{
${ }^{30}$ It is not entirely clear how to think about the relation between non-deducibility and causal efficacy or the relative importance for strong emergence. If properties are deducible, then this seems to cut against their causal autonomy (or a freedom to cause this or that), though it may not be incompatible with their being valuable elements in causal explanations. In any case, we need not settle this issue here. See Schröder (1998) for discussion. He maintains that causal impact is more important to emergence, though he has a particular kind of deducibility in mind and in particular is thinking about causal impact through the relatedness of the parts of the supervenience base of an emergent property.

${ }^{31}$ For example, Barnes (2012:883-4) characterizes the emergent in terms of a 'robust ontological commitment,' as these will be new fundamental (though dependent) entities on her understanding of it. Barnes does not explicitly characterize this ontological commitment causally, but at times she says things indicative of a new causal role of emergent entities.

${ }^{32}$ I will note, though, that part of Wahlberg's concerns involves his rejection of the possibility of downward causation, and there are special things that we can say about downward causation in this context that will be brought out below.

${ }^{33}$ Lawson (op. cit.) also takes elements of social systems to be efficacious in this sense and to indeed be emergent because of it, though he does not characterize the way in which these elements emerge and has a different conception of downward causation than that discussed below.

34 This goes well with a tradition of so-called 'intralevelist' strategies for defending the efficacy of various properties and objects. This involves arguing that higher-level events somehow beat out lower-level events for causing higher-level effects, or else showing that lower-level events are unable to offer a competing causal
} 
maintain that strong emergence requires more. Some take strong emergence to require 'downward causation,' or the causing of physical effects. ${ }^{35}$ Of course, it is highly controversial whether downward causation is even possible, and so whether it should be a necessary feature of strong emergence, but still it may be fair to wonder whether we should be tempted to say that system-based social properties are strongly emergent in this sense. And I think we should be. What I want to say quickly to conclude this section is that there is a prima facie case for thinking that system-based social properties downwardly cause. Moreover, one of the biggest reasons for denying the possibility of downward causation seems defused (or at least challenged) given how system-based social properties emerge.

It is not hard to imagine cases of some of the events occurring in social systems as having certain physical effects. We would readily say that our market economy has had devastating effects on the environment. Or, we might say that a referee's calling off-sides in a football game made viewers furious. Or, perhaps Amy's pawn-movement made her opponent's heartrate quicken. None of these examples are beyond objection. Someone could argue in each case that the effect in question is not really physical after all, or else that the effect is physical but the best causal explanation for it is physical as well. The presence of these other interpretations is predicable, but the case is there to be made that system-based social properties do have legitimate downward effects.

Further, there is a reason to be optimistic that these apparent cases of downward causation will pan out. Typically, the prospects for downward causation are cast in doubt by the fact that we assume that physical effects are not overdetermined, and we also assume that physical effects have sufficient physical causes proximately causing them. Put colloquially, physical events already have physical causes, so there seems to be no causal work left for higher-level properties to do via downward causation. However, the way in which we have characterized social system property emergence puts pressure on this line of thought.

Why think that physical effects have sufficient physical causes that are proximately causing them? In many cases, there is a clear physical event present that we judge to be sufficient for immediately bringing about the physical effect. It is the striking of one billiard ball by another, we may say, that obviously causes the billiard ball to zoom off in the other direction. Even in our cases of apparent downward causation, we might be able to imagine certain physical causes that proximately cause the effects. Perhaps the environmental effects are proximately caused by moving around natural resources, for instance.

However, it is not always obvious what the proximate physical cause in a case is. This is especially true when thinking about our cases, because system-based social properties do not supervene on purely local physical properties. Their supervenience base ends beyond and before their physical constitutors. (The wood-movement as an event may be specially related to the pawn-movement, but the pawn-movement depends on much more.) So, it is not obvious that what is physically local to the situation is sufficient to compete as a cause of the effect. We may assume that there will be a proximate physical cause because we see them so regularly, but why not think our cases of downward causation are just rarer such that they are the exception to this generalization?

In response, there are a few reasons we might give, and one significant reason is that the physical world seems to be in some way causally closed or complete such that all physical

explanation (Thomasson 1998; Gibbons 2006; Silver forthcoming). This kind of strategy is extremely controversial, though, and it goes well beyond our purposes to argue for it here.

${ }^{35} \mathrm{Kim}$ (2006) claims this explicitly. (This should be no surprise given that Kim thinks that higher-level properties can only cause other higher-level properties via downwardly causing their supervenience base.) 
effects have sufficient physical causes. There is a fair amount of history for accepting a principle of causal closure, ${ }^{36}$ and a natural way to specify this idea would be to say that every physical event has a sufficient proximate physical cause. This would mean that every event would have a causal explanation that is entirely physical - the effect has a proximate physical cause which has a proximate physical cause and so on. This is a way that we might understand the causal closure principle, ${ }^{37}$ and understanding it this way appears to conflict with the possibility of downward causation (Gillett 2002). However, as a number of scholars have noted, this is not the only version of the principle available, and it may be that a weaker version of the principle is both plausible and compatible with downward causation. ${ }^{38}$

In fact, I think there is another plausible causal closure principle that that is compatible with downward causation especially given how system-based social properties have been argued to emerge. Rather than thinking that closure requires that an event's causal history be entirely physical, we may think that what really matters for the closure of physics is that there are no physical events that are not ultimately explained in terms of or caused by other physical events. That is, there are no physical events being caused and causing that cannot be accounted for ultimately by physics. And downwardly causing system-based social properties accommodate this intuition. We saw how system-based social properties emerge in such a way that their property instances are either caused by the instantiation of other system-based social properties or else by physical elements in their proximate physical circumstances. So, even if a physical event has a social system property instance as its sole cause, the explanation of that physical event will nevertheless ultimately be physical in the sense that the ultimate causes of the social system property are physical. All physical effects are explained in terms of other physical phenomenon, even if those physical causes are not proximal to their physical effects. ${ }^{39}$

By motivating a version of causal closure on which proximate physical causation is not guaranteed, we undermine our reason for thinking that any downward causation threatens overdetermination. A given case of apparent downward causation may seem to be in competition with some proximate physical cause, but cases where it is not quite clear what proximate physical event is present and threatening suggests that the downward causation in these cases is legitimate. This is merely suggestive, though, as we would need to more fully argue for the presence of downward causation and the absence of proximate physical causes

\footnotetext{
36 See Papineau (2000) for some historical context about physicalism and the closure principle, and Robb \& Heil (op. cit.:sec.2.4) for a more reflective discussion of the principle itself and some of the stronger or weaker versions of it.

${ }^{37} \mathrm{Kim}$ (2000:40) glosses closure in just this way: "One way of stating the principle of physical causal closure is this: If you pick any physical event and trace out its causal ancestry or posterity, that will never take you outside the physical domain." Papineau (op. cit.) also characterizes closure in this way, where physical events have a 'purely physical' history.

38 Prosser (2012) offers a reading of causal closure that purports to allow for downward causation, though his view of this will require indeterministic laws at the base level. Garcia (2014) argues directly against needing to understand closure in terms of proximal causation. Also see Moore (2019), which catalogues a whole menu of ways scholars have seemed to relax the causal closure principle in order to avoid exclusion worries.

39 O'Connor and Wong at one point also quickly note that in some sense the products of downward causation will be contained in the causal profiles of the physical causes of emergent properties (op. cit::668), though I think they severely undersell this point. If what reductionists are perhaps most worried about is some sort of inexplicable invasion or intrusion upon the regular goings-on of physics by higher-level properties, then recognizing that ultimately local intrusions by higher-level properties are causally explained by physics itself should significantly quell their concerns. What's more, this is a response to the worry concerning closure that will be available to any account of emergence in which the emergence involves upwards causation.
} 
to sufficiently argue the point. And concerns likely remain..$^{40}$ However, what this does show is that there is some case to be made (more so than normal) that diachronically emerging ${ }^{41}$ system properties are strongly emergent.

\section{Conclusion}

Although it seems clear that the properties of our social world are non-identical with the properties of the natural sciences, little is written to tell a story for how the former are related to and come from the latter. The framework most developed for thinking about this kind of relationship involves the concept of emergence, but one rarely sees scholars in social ontology talking in these terms (despite the heated debates over methodological individualism or collective mentality). So, my primary aim has been to think about how we might start to fill this gap.

After attempting to clarify the properties at issue and their relation to systems, my aim has been twofold: First, I wanted to juxtapose how these properties seem to emerge with how emergence is often argued to proceed. And, second, I wanted to consider what could be said about the kind of emergence we end up with relative to the kinds of emergence that are often distinguished and argued about.

What we found was that the fact that the supervenience base for these properties is often in part historical and non-local suggests that they emerge diachronically, yet not as diachronic emergence has been portrayed. Moreover, although I think that emergence that proceeds in this fashion is compatible with strong emergence involving downward causation, whether these properties really do strongly emerge ultimately depends on whether we hold a tapestry of views concerning the nature of the rules of the systems at hand, the possibility of wide causation (or causation involving relational properties), and, indeed, the view of our own free agency. In each case, I took no stand the debate in question, but it is hopefully helpful to see how the strength of the emergence of system-based social properties depends on these debates. More lucratively, it is at least suggestive that there is a collection of views that would get us to the ontologically serious conclusion that system-based social properties are strongly emergent. $^{42}$

\footnotetext{
${ }^{40}$ Another likely concern is that there is simply something spooky about downward causation, a sense that physical events really must have proximate physical causes (regardless of our closure principle), perhaps because it is not clear how social events make contact with the physical world or that physical effects require physical changes. We lack the space to do this kind of concern justice; however, a proponent of downward causation can say a few things quickly in response. First, we can grant that physical effects cannot occur without some proximate physical change to their environment, though we may deny that any of those changes constitute events that compete as causes of the effect. Second, we may adopt different ways of thinking about the downward causation, perhaps framing downward causes as constraints on lower-level facts (as Chalmers [op. cit.] does).

41 The case made here could also be used to argue that other properties that emerge causally are in a position to downwardly cause while abiding by causal closure. However, it would also need to be that there is no clear proximate physical events competing to cause the effects in question, and we saw that the distal supervenience base for social systems properties provides some reason for why they in particular might lack such competition.

${ }^{42}$ Acknowledgements: I would like to thank each of reviewers of this manuscript for valuable input.
} 
Kenneth Silver

Penultimate copy

\section{References}

Baker, L. (2000) Persons and Bodies: A Constitution View. Cambridge Studies in Philosophy Series, Cambridge University Press.

Barnes, E. (2012) "Emergence and Fundamentality," Mind, 121:484, pg.873-901.

Bedau, M. A. (1997) "Weak Emergence," Philosophical Perspectives, 11, pg.375-399.

Bennett, K. (2008) "Exclusion Again," in Being Reduced: New Essays on Reductive Explanation and Special Science Causation, Eds. Kallestrup, J. and Hohwy, J. Oxford: Oxford University Press. pg.280-305.

Bickhard, M. H. (2008) “Social Ontology as Convention,” Topoi, 27:1-2, pg.139-149.

Bickle, J. (2019) "Multiple Realizability," The Stanford Encyclopedia of Philosophy (Spring 2019 Edition), Ed. Zalta, E. N. URL = https://plato.stanford.edu/archives/spr2019/entries/multiple-realizability/.

Brennan, G. \& Tullock, G. (1982) "An Economic Theory of Military Tactics: Methodological Individualism at War," Journal of Economic Behavior and Organization, 3:3, pg.225-242.

Brynjarsdóttir, E. M. (2018) The Reality of Money: The Metaphysics of Financial Value. Rowman \& Littlefield International.

Chalmers, D. (2006) "Strong and Weak Emergence," in The Re-Emergence of Emergence, Eds. Clayton, P. and Davies, P. Oxford University Press. pg.244-255.

Crane, T. (2001) "The Significance of Emergence," in Physicalism and its Discontents, Eds. Loewer, B. and Gillett, G. Cambridge University Press. pg.207-224.

de Muijnck, W. (2002) “Causation by Relational Properties," Grazer Philosophische Studien, 65:1, pg.123-137.

Demeulenaere, P. (2011) "Introduction," in Analytical Sociology and Social Mechanisms, Ed. Demeulenaere, P. Cambridge: Cambridge University Press. pg.1-30.

Elder-Vass, D. (2010) The Causal Power of Social Structures. Cambridge, UK: Cambridge University Press.

Elder-Vass, D. (2014a) "Social Entities and the Basis of Their Powers," in Rethinking the Individualism-Holism Debate, Eds. Zahle, J. and Colin, F. Dordrecht, The Netherlands: Springer. pg.39-53.

Elder-Vass, D. (2014b) "Redescription, Reduction, and Emergence: A Response to Tobias Hansson Wahlberg," Philosophy of the Social Sciences, 44:6, pg.792-897.

Elster, J. (1983) Explaining Technical Change: A Case Study in the Philosophy of Science. Cambridge: Cambridge University Press.

Epstein, B. (2015) The Ant Trap: Rebuilding the Foundations of the Social Sciences. Oxford University Press.

Fodor, J. (1974) "Special Sciences, or The Disunity of Science as a Working Hypothesis," Synthese, 28, pg.97-115.

Ganeri, J. (2011) "Emergentisms, Ancient and Modern," Mind, 120:479, pg.671-703.

Garcia, R. K. (2014) "Closing in on Causal Closure," Journal of Consciousness Studies, 21:1-2, pg.96-109.

Gibbons, J. (2001) "Knowledge in Action," Philosophy and Phenomenological Research, 62:3, pg. 679-600.

Gibbons, J. (2006) "Mental Causation without Downward Causation," Philosophical Review, 115:1, pg.79-103.

Gillett, C. (2002) "Strong Emergence as a Defense of Non-Reductive Physicalism," Principia: An International Journal of Epistemology, 6:1, pg.87-120. 
Kenneth Silver

Hédoin, C. (2015) “Accounting for Constitutive Rules in Game Theory," Journal of Economic Methodology, 22:4, pg.439-461.

Heil, J. \& Mele, A. (1993) Mental Causation. Oxford: Clarendon Press.

Humphreys, P. (1996) “Aspects of Emergence,” Philosophical Topics, 24:1, pg.53-69.

Humphreys, P. (1997) "How Properties Emerge,” Philosophy of Science, 64, pg.1-17.

Humphreys, P. (2008) "Synchronic and Diachronic Emergence," Minds and Machines, 18:4, pg. 431-442.

Johnston, M. (1992) “Constitution is Not Identity," Mind, 101:401, pg.89-105.

Kim, J. (1999) “Making Sense of Emergence," Philosophical Studies, 95, pg.3-36.

Kim, J. (2000) Mind in a Physical World: An Essay on the Mind-Body Problem and Mental Causation, First MIT Press paperback edition.

Kim, J. (2006) "Emergence: Core Ideas and Issues," Synthese, 151, pg.547-559.

Kincaid, H. (1986) "Reduction, Explanation and Individualism," Philosophy of Science, 53, pg.492-513.

Kirchhoff, M. (2014) "In Search of Ontological Emergence: Diachronic, But NonSupervenient," Axiomathes, 24, pg.89-116.

Korman, D. Z. (2020) "The Metaphysics of Establishments," Australasian Journal of Philosophy, 98, pg.434-448.

Lau, J. \& Deutsch, M. (2019) “Externalism About Mental Content," The Stanford Encyclopedia of Philosophy, E. N. Zalta (ed.), URL = https://plato.stanford.edu/archives/fall2019/entries/content-externalism/.

Lawson, T. (2013) "Emergence and Social Causation," in Powers and Capacities in Philosophy: The New Aristotelianism, Eds. R. Groff \& G. Greco. New York: Routledge.

Lewis, D. (1972) "Psychological and Theoretical Identifications," Australasian Journal of Philosophy, 50, pg.249-258.

Lewis, D. (1979) "Scorekeeping in a Language Game," Journal of Philosophical Logic, 8:3, pg.339359.

List, C. (2019) Why Free Will is Real. Harvard University Press.

List, P. \& Spiekermann, K. (2013) "Methodological Individualism and Holism in Political Science: A Reconciliation," American Political Science Review, 107:4, pg.629-643.

Macdonald, G. (2007) "Emergence and Causal Powers," Erkenntnis, 67:2, pg.239-253.

McLaughlin, B. (1992) "The Rise and Fall of British Emergentism," in Emergence or Reduction? Eds. Beckermann, A., Flohr, H., and Kim, J. Berlin: De Gruyter, pg.49-93.

Mitrović, B. (2017) "Is Methodological Realizability a Valid Argument Against Methodological Individualism?" Philosophy of the Social Sciences, 47:1, pg.28-43.

Moore, D. (2019) "Causal Exclusion and Physical Causal Completeness," Dialectica, 73:4, pg.479-505.

Noonan, H. W. (1993) “Constitution is Identity," Mind, 102:405, pg.133-46.

O'Connor, T. and Wong, H. (2005) "The Metaphysics of Emergence," Noûs, 39:4, pg.658678.

Papineau, D. (2000) “The Rise of Physicalism," in Physicalism and Its Discontents. Eds. C. Gillett \& B. M. Loewer. Cambridge University Press. pg.3-36.

Pereboom, D. (2002) "Robust Nonreductive Materialism," Journal of Philosophy, 99:10, pg.499531.

Polger, T. W. \& Shapiro, L. A. (2016) The Multiple Realizability Book. Oxford: Oxford University Press.

Popper, K. (1945) The Open Society and Its Enemies, 2 vols. London: Routledge and Kegan Paul. Prosser, S. (2012) “Emergent Causation,” Philosophical Studies, 159, pg.21-39. 
Kenneth Silver

Putnam, H. (1967) "Psychological Predicates," in Art, Mind, and Religion, Eds. Capitan, W. H. and Merrill, D. D. Pittsburgh, PN: University of Pittsburgh Press.

Putnam, H. (1973) Philosophy and Our Mental Life. Berkeley, CA: Symposium.

Rapport, N. (2017) "Being Undisciplined: Doing Justice to the Immensity of Human Experience," The Sociological Review Monographs, 65:1, pg.196-204.

Robb, D. \& Heil, J. (2019) "Mental Causation," The Stanford Encyclopedia of Philosophy (Summer 2019 Edition). Ed., Zalta, E. N. URL = https://plato.stanford.edu/archives/sum2019/entries/mental-causation/.

Sartenaer, O. (2015) "Synchronic vs. Diachronic Emergence: A Reappraisal," European Journal for Philosophy of Science, 5:1, pg.31-54.

Sawyer, K. (2002) "Nonreductive Individualism: Part I-Supervenience and Wild Disjunction," Philosophy of the Social Sciences, 32, pg.537-559.

Schröder, J. (1998) "Emergence: Non-Deducibility or Downwards Causation?" The Philosophical Quarterly, 48:193, pg.433-452.

Schweikard, D. P. \& Schmid, H. B. (2013) "Collective Intentionality," The Stanford Encyclopedia of Philosopby (Summer 2013 Edition), Ed. Zalta, E. N. URL = https://plato.stanford.edu/archives/sum2013/entries/collective-intentionality/.

Searle, J. (1995) The Construction of Social Reality. New York: Free Press.

Silberstein, M. (2017) "Strong Emergence No, Contextual Emergence Yes," Philosophica, 91, pg.145-192.

Silberstein, M. and McGeever, J. (1999) "The Search for Ontological Emergence," The Philosophical Quarterly, 49:195, pg.182-200.

Silver, K. (forthcoming) "Causal Exclusion and Ontic Vagueness," Australasian Journal of Philosophy, pg.1-14. DOI: 10.1080/00048402.2020.1823443.

Thomasson, A. (1998) “A Nonreductive Solution to Mental Causation," Philosophical Studies, 89, pg.181-195.

Wahlberg, T. H. (2014a) "Elder-Vass on the Causal Power of Social Structures," Philosophy of the Social Sciences, 44(6), pg.774-791.

Wahlberg, T. H. (2014b) "Causally Redundant Social Objects: Rejoinder to Elder-Vass," Philosophy of the Social Sciences, 44(6), pg.798-809.

Wahlberg, T. H. (2020) "Causal Powers and Social Ontology," Synthese, 197, pg.1357-1377.

Watkins, J. W. N. (1957) "Historical Explanation in the Social Sciences," in Modes of Individualism and Collectivism, Ed. O’Neill, J. London: Heinemann. pg.143-178.

Williamson, T. (1998) "The Broadness of the Mental: Some Logical Considerations," Nồs, 32, Supplement: Philosophical Perspectives, 12, pg. 389-410.

Yablo, S. (2003) "Causal Relevance," Philosophical Issues, 13:1, pg. 316-329.

Zahle, J. (2014a) "Holism, Emergence, and The Crucial Distinction," in Rethinking the Individualism-Holism Debate, Eds. Zahle, J. and Colin, F. Dordrecht, The Netherlands: Springer. pg.177-196.

Zahle, J. (2014b) "How to Circumscribe Individualist Explanations: A Reply to Elder-Vass," Philosophy of the Social Sciences, 44(6), pg.810-816.

Zahle, J. \& Kincaid, H. (2019) “Why Be a Methodological Individualist?” Synthese, 196, pg.655675. 